\title{
Spontaneous rupture of the spleen in infectious mononucleosis
}

\author{
P. W. R. LEE \\ M.B., F.R.C.S.
}

M. WhitTAKER

M.B., F.R.C.S.

T. J. Hali.

M.B., F.R.C.S.

\author{
Department of Surgery, Leeds (St James's) University Hospital
}

\begin{abstract}
Summary
Two cases of spontaneous rupture of the spleen as a complication of infectious mononucleosis are reported. The literature is briefly reviewed and emphasis placed on the need for awareness of this rare complication.

\section{Introduction}

Spontaneous rupture of the spleen is a rare but well recognized complication of infectious mononucleosis (Rawsthorne, Cole and Kyle, 1970; York, 1962; Hedrick and Lettner, 1965). During a period of 8 weeks the authors had the unique opportunity of managing two such cases.
\end{abstract}

\section{Case No. 1}

A 22-year-old man was admitted as an emergency, his general practitioner having diagnosed spontaneous rupture of the spleen during infectious mononucleosis. For 10 days he had had a sore throat, painful lymph nodes and malaise. The clinical diagnosis of infectious mononucleosis had been confirmed by his doctor using a Paul Bunnell test. Eighteen hours before admission he had turned over quickly in bed and noted the sudden onset of left hypochondral pain which rapidly radiated to the left shoulder-tip. He vomited three times at the onset of the pain.

On admission he was pale and anaemic, but not shocked, with a pulse of $80 / \mathrm{min}$, and a BP of $110 / 80$ $\mathrm{mmHg}$. Generalized lymphadenopathy was present. Examination of the abdomen showed generalized tenderness and guarding, most marked in the left hypochondrium. Rectal examination showed tenderness in the rectovesical pouch.

Through a right paramedian incision, laparotomy revealed a large amount of free blood and clot. The enlarged, friable spleen was almost completely devoid of capsule. The spleen was removed and the abdomen closed with a drain. The postoperative course was uneventful. The pathologist's report showed the spleen to weigh $390 \mathrm{~g}$ with evidence of

Correspondence: Mr P. W. R. Lee, Department of Surgery, Leeds (St James's) University Hospital, Beckett Street, Leeds. rupture towards the hilum. Histologically the substance was infiltrated with atypical mononuclear cells with infiltration and degeneration of the splenic capsule.

\section{Case No. 2}

A 26-year-old male was admitted as an emergency with a 4-day history of vague abdominal pain, left shoulder-tip pain, anorexia and malaise. At the time of admission he was pyrexial $\left(39^{\circ} \mathrm{C}\right)$ with bilateral cervical lymphadenopathy. Minimal lower abdominal tenderness was present but the spleen was not palpable.

Routine blood investigations showed a white cell count of $7,900 / \mathrm{mm}^{3}$ with $66 \%$ lymphocytes, many of which were atypical. A Paul Bunnell test was positive and confirmed the diagnosis of infectious mononucleosis. The patient's symptoms remained unchanged until day 5 of admission, when he complained of a sudden increase in the severity of both his abdominal and shoulder-tip pain. On examination he was peripherally collapsed with a pulse of $120 / \mathrm{min}$, and a BP of $80 / 60 \mathrm{mmHg}$. He had generalized abdominal tenderness maximal in the left upper quadrant with rebound tenderness in this area.

A diagnosis of ruptured spleen was made and at laparotomy an enlarged, soft spleen ruptured at its upper pole was removed together with $1500 \mathrm{ml}$ of intraperitoneal blood. Apart from a continued fever for the first $\mathbf{4}$ days the patient made an uninterrupted recovery and was discharged home on the fourteenth postoperative day.

The pathologist's report showed the spleen to weigh $450 \mathrm{~g}$. The upper pole was covered in blood clot where a 4-cm laceration was present. Histological sections showed changes typical of infectious mononucleosis.

\section{Discussion}

The rarity of spontaneous rupture of the spleen as a complication of infectious mononucleosis is demonstrated by the fact that until 1970 only fifty-five cases had been recorded in the world 
literature (Rawsthorne et al., 1970). In the 12-year period since the report of Wetherill and Oldfield in 1963 , no cases of the complication have been recorded in the files of the two major Leeds hospitals which serve a population of 600,000 people. The symptoms and signs of the complication are similar to those of traumatic rupture of the spleen with shoulder-tip pain being prominent.

It is suggested that the soft, pathologically enlarged spleen may be ruptured by trauma which would normally be of no consequence, such as the act of coughing, vomiting or defaecation (Beck, Blundell and Meban, 1968). In Case no. 1, it appears that the act of turning over in bed was sufficient to precipitate the rupture while in case no. 2 no precipitating factor could be identified.

Although rupture occurred in these cases on the ninth and tenth day of the illness respectively, it is suggested that the complication does not usually occur until the tenth to twentieth day when the pathological changes in the spleen are at their greatest.
In conclusion, it is emphasized that an awareness of this complication must be retained if the high mortality rate of $33 \%$ associated with the complication (Smith, 1956) is to be avoided.

\section{Acknowledgments}

We thank Mr H. S. Shucksmith and Mr G. Wilson for permission to report details of these patients.

\section{References}

Beck, J.R., Blundell, G. \& Meban, S. (1968) Rupture of the spleen in infectious mononucleosis. Ulster Medical Journal, $37,56$.

HedRick, H.E. \& LetTNer, H.T. (1965) Rupture of the spleen. Journal of Kansas Medical Society, 66, 374.

Rawsthorne, G.B., Cole, T.P. \& Kyle, J. (1970) Spontaneous rupture of the spleen in infectious mononucleosis. British Journal of Surgery, 57, 396.

Smith, J.N. (1956) Complications of infectious mononucleosis. Annals of Internal Medicine, 44, 861.

Wetherill, J.H. \& Oldfield, M.C. (1963) Rupture of the spleen and thrombocytopaenia in glandular fever. Lancet, $\mathbf{i}$, 636.

YORK, W.H. (1962) Spontaneous rupture of the spleen. Report of a case secondary to infectious mononucleosis. Journal of the American Medical Association, 179, 170. 